\title{
APRESENTAÇÃO DO DOSSIÊ EM MEMÓRIA DE ISTVÁN MÉSZÁROS
}

\author{
Caio Antunes ${ }^{1}$ \\ O bom educador é alguém que \\ inspira a autoeducação \\ (István Mészáros)
}

Há exato um ano falecia István Mészáros.

Autor audacioso e potente, legou-nos uma obra vasta e profunda, original e polêmica, composta de mais de duas dezenas de livros traduzidos para diversas línguas, em vários países, e uma imensidão de artigos e capítulos espalhados por incontáveis revistas e coletâneas. ${ }^{2}$ Mais do que um rigoroso estudioso de Marx, Mészáros é um continuador de sua obra - sem jamais abandonar, que fique claro, seus marcos teóricos e políticos. Seu pensamento suscita, ontem como hoje, em muitas partes do globo ${ }^{3}$, intensos debates.

A entrada de seu pensamento no Brasil dá-se no ano de 1981, com a publicação de Marx: teoria da alienação, seguida de outros livros e artigos, publicados ao longo das décadas de 1980 e 1990. Mas, é com a publicação de sua Opus Magnum, em 2002, que Mészáros firma seu caminho para tornar-se um autor central no debate crítico e emancipatório brasileiro, nas mais variadas áreas do conhecimento.

O dossiê que aqui se apresenta indica, de certo modo, um pouco desta trajetória e influência, marcando, ainda que brevemente, e em posições/interpretações por

\footnotetext{
1 Doutor em Educação pela Universidade Estadual de Campinas (UNICAMP), onde também concluiu a Licenciatura em Educação Física e o Mestrado em Educação. Atua como professor da Faculdade de Educação Física e Dança da Universidade Federal de Goiás (UFG). E-mail: antunescs@uol.com.br

2 Ao fim desta Apresentação consta uma lista dos livros publicados por István Mészáros. Para maiores informações acerca de sua obra, consultar < https://marxismo21.org/istvan-meszaros-1930-2017/>.

${ }^{3}$ Basta mencionar, com indício, o fato de que sua obra de maior projeção internacional (Marx's theory of alienation (MÉSZÁROS, 1972)), lançada em 1970, chegava à terceira edição apenas 18 meses após sua publicação.
} 
vezes distintas, uma pequena parte da variedade e da importância de temas abordados e suscitados pela obra meszariana.

Este dossiê se abre com uma delicada homenagem de Jorge Giordani ${ }^{4}$ a seu grande professor, amigo e interlocutor. De início mais afetivo, a homenagem traça um rápido painel teórico e biográfico de Mészáros, desde a saída forçada da Hungria, após o levante de 1956, até o final de sua vida em 2017, na Inglaterra.

Esta homenagem é seguida de uma entrevista a mim concedida por Ricardo Antunes, interlocutor e amigo próximo de István Mészáros, com quem durante décadas estabeleceu intenso e profícuo diálogo. Nela, são abordados temas que vão desde a inserção do pensamento de Mészáros no Brasil, até o último grande projeto do filósofo húngaro - deixado inacabado.

Dos artigos seguintes, o primeiro, de autoria do italiano Diego Alberto Biancolin, traduzido para o português por Stefano Mota5, no qual o autor aponta aproximações e distanciamentos entre as formulações de István Mészáros e de seu mestre, György Lukács, mais precisamente entre os clássicos História e Consciência de Classe, de 1923, e Para Além do Capital, de 1995. O segundo artigo, de Gláucia Lelis Alves, perquire a categoria da ideologia, indicando sua fulcral funcionalidade para manutenção da reprodução da ordem burguesa, a partir do deslocamento, operado pelo Estado burguês, do conflito para a conciliação de classes com vistas a justificar a desigualdade socialmente criada pelo sistema, considerada como algo natural.

Na sequência estão dois artigos que abordam de forma complementar a categoria da igualdade substantiva, absolutamente fundamental para o sistema de Mészáros 6 . O primeiro, de Kaithy das Chagas Oliveira, confronta a substância meramente formal do conceito burguês de liberdade, importante elemento do processo de manutenção da subordinação estrutural do trabalho ao capital, com a noção meszariana da igualdade substantiva, elemento central da estratégia socialista na construção de um mundo para além do capital. 0 segundo, de autoria de Lenin Tomazett Garcia e Anita

\footnotetext{
4 Agradeço as gentilíssimas contribuições de Maria Orlanda Pinassi e Martin Scarpacci para a tradução e de Gláucia Lelis Alves para a revisão da tradução deste artigo.

5 Agradeço as gentilíssimas contribuições de Stefano Mota para a tradução deste artigo.

${ }^{6} \mathrm{O}$ filosofo húngaro chega mesmo a afirmar que a igualdade substantiva "não é apenas um dos muitos princípios orientadores do empreendimento socialista. Ocupa posição-chave no interior da estrutura categorial geral da alternativa hegemônica do trabalho à ordem de reprodução social estabelecida, já que todos os demais princípios orientadores vitais da estratégia socialista podem apenas adquirir seu sentido pleno em íntima conjunção com a exigência da igualdade substantiva" (MÉSZÁROS, 2009, p. 272).
} 
Cristina Azevedo Resende, aponta o referido conceito como chave para a apreensão da concreticidade dos desenvolvimentos históricos do sistema do capital, uma vez que, no interior deste, a igualdade substantiva se mostra estruturalmente impossibilitada de existir.

Os artigos subsequentes, primeiro o de Lívia de Cássia Godoi Moraes, aborda o candente tema da emancipação feminina - tema enfrentado por Mészáros já na década de 1990 -, tanto em relação à divisão sociosexual do trabalho, quanto em relação ao interior da vida na família nuclear, sob a ordem sociometabólica do capital. 0 segundo, de Henrique Tahan Novaes, enfrenta a categoria da "produção destrutiva" - inversão operada por Mészáros da máxima schumpeteriana da "destruição produtiva" -, de modo a articular a ofensiva do agronegócio no Brasil e a necessária e incontornável devastação que ela impõe ao movimento interno da lógica do sistema do capital, apontando como alternativa de enfrentamento ao agronegócio as lutas pela construção da agroecologia, impulsionadas principalmente pelo Movimento dos Trabalhadores Sem Terra (MST), a partir da própria discussão meszariana acerca da "revolução verde".

O último bloco da seção traz mais dois artigos que abordam a temática educacional. No primeiro deles, eu, Caio Antunes, busco compreender a categoria "educação" no interior do sistema teórico-filosófico-político de Mészáros, onde aponto, por um lado, a necessidade de sua apreensão em seu sentido mais amplo e, por outro, seu papel central na luta emancipatória da humanidade. 0 segundo artigo, de autoria de Janaynna de Moura Ferraz, Deise Luiza Ferraz e Bárbara Katherine Faris Biondini, analisa o sistema educacional brasileiro apontando as relações entre a precariedade do trabalho, o nível de escolaridade ou a qualidade da educação e a intensificação da exploração do trabalho e apontam para a necessidade de sua superação.

Fungindo à regra da RTPS - Revista Trabalho, Política e Socidedade que prioriza publicações dos últimos dois anos, justificadamente a seção final do dossiê traz duas resenhas que, embora refiram-se a livros mais antigos de Mészáros, enfatizam pontos centrais do debate suscitado por sua obra e adentram polêmicas advindas das diferentes apreensões e interpretações de seu sistema. Na primeira resenha, traduzida para o português por Gláucia Lelis Alves7, o italiano Antonino Infranca enfrenta a difícil tarefa de resenhar o colossal Para Além do Capital, situando rapidamente a obra na trajetória intelectual e política de Mészáros e demarcando

\footnotetext{
7 Agradeço a gentilíssima contribuição de Gláucia Lelis Alves para a tradução deste artigo.
} 
alguns de seus pontos fundamentais. Na segunda, Demétrio Cherobini resenha o texto Produção Destrutiva e Estado Capitalista, criticando, de um lado, determinadas interpretações da obra meszariana e, de outro lado, demarcando incisivamente a necessidade de uma retomada deste pequeno texto ${ }^{8}$ para uma adequada apreensão da formulação de Mészáros como um todo.

A humanidade vive tempos sombrios. A irracionalidade da determinação econômica se manifesta nas mais variadas formas: da devastação ambiental desenfreada aos tantos irracionalismos teóricos, passando pela multiplicação, em muitas partes do globo, dos mais grotescos neofascismos.

A obra de Mészáros é colossal porque colossal é o desafio que temos à nossa frente, como humanidade. E nesta imensa tarefa histórica de "transformação socialista plenamente sustentável" (MÉSZÁROS, 2007, p. 293), “o papel dos educadores e sua correspondente responsabilidade não poderiam ser maiores" (MÉSZÁROS, 2005, p. 58).

Mas recordemo-nos aqui da "educação do educador"! Assevera Marx que "a coincidência entre a altera[ção] das circunstâncias e a atividade ou automodificação humanas só pode ser apreendida e racionalmente entendida como prática revolucionária" (MARX; ENGELS, 2007, p. 534). Isto implica o amplo e profundo processo de passagem da "classe-em-si" para a "classe-para-si", conforme Marx, ou da "consciência de classe contingente" para a "consciência de classe necessária", conforme Mészáros. Em outras palavras, o processo de "automodificação humana" constitui-se, em verdade, em um processo revolucionário de "autoeducação" (MÉSZÁROS, 2006, p. 172).

Eis nossa singela homenagem a este grande intelectual e admirável ser humano que foi István Mészáros.

\section{Referências}

LUKÁCS, György. História e consciência de classe: ensaios de dialética marxista. Trad. Telma Costa. Porto: Elfos, 1974.

\footnotetext{
8 Originalmente publicado no brasil na década de 1980, foi depois incluído no Para Além do Capital.
} 
MARX, Karl. Miséria da filosofia: resposta à Filosofia da Miséria do Sr. Proudhon. Trad. José Paulo Netto. São Paulo: Expressão Popular, 2009.

MARX, Karl; ENGELS, Friedrich. A ideologia alemã: crítica da mais recente filosofia alemã em seus representantes Feuerbach, B. Bauer e Stirner, e do socialismo alemão em seus diferentes profetas (1845 - 1846). Trad. Rubens Enderle, Nélio Schneider e Luciano Cavini Martorano. São Paulo: Boitempo, 2007.

MÉSZÁROS, István. A educação para além do capital. Trad. Isa Tavares. São Paulo: Boitempo, 2005.

$\overline{2006}$.

A teoria da alienação em Marx. Trad. Isa Tavares. São Paulo: Boitempo,

. Estrutura social e formas de consciência: a determinação social do método.

Trad. Luciana Pudenzi, Francisco Raul Cornejo e Paulo Cesar Castanheira. São Paulo: Boitempo, 2009.

Filosofia, ideologia e ciência social: ensaios de negação e afirmação. Trad. Ester Vaisman. São Paulo: Boitempo, 2008.

Marx: a teoria da alienação. Trad. Waltensir Dutra. São Paulo: Zahar, 1981.

Marx's theory of alienation. New York: Harper Torchbooks, 1972.

O desafio e o fardo do tempo histórico: o socialismo no século XXI. Trad. Ana Aguiar Cotrim e Vera Aguiar Cotrim. São Paulo: Boitempo, 2007.

Para além do capital: rumo a uma teoria da transição. Trad. Paulo Cesar Castanheira e Sérgio Lessa. São Paulo: Boitempo, 2002.

. Produção destrutiva e Estado capitalista. Trad. Georg Toscheff. São Paulo: Ensaio, 1989.

PANIAGO, Cristina; PINASSI, Maria Orlanda; ANTUNES, Caio; CHEROBINI, Demétrio. Dossiê István Mészáros: (1930-2017). São Paulo, 04 jan. 2018. Disponível em: https://marxismo21.org/istvan-meszaros-1930-2017/. Acesso em 24 ago. 2018.

\section{Lista de Livros de István Mészáros}

MÉSZÁROS, István. Szatira és valóság. Budapeste: Szépirodahyli Könyvkiadó, 1955. 
MÉSZÁROS, István. La rivolta degli intellettuali in Ungheria. Turim: Einaudi, 1958. (Edição brasileira: MÉSZÁROS, István. A revolta dos intelectuais na Hungria. Trad. João Pedro Alves Bueno. São Paulo: Boitempo, 2018)

MÉSZÁROS, István. Attila József e l'arte moderna. Milão: Lerici, 1964.

MÉSZÁROS, István. Marx's theory of alienation. London: Merlin Press, 1970. (Edições brasileiras: 1) MÉSZÁROS, István. Marx: a teoria da alienação. Trad. Waltensir Dutra. Rio de Janeiro: Zahar, 1981; 2) MÉSZÁROS, István. A teoria da alienação em Marx. Trad. Isa Tavares. São Paulo: Boitempo, 2006; 3) MÉSZÁROS, István. A teoria da alienação em Marx. Trad. Nélio Schneider. São Paulo: Boitempo, 2016.)

MÉSZÁROS, István. Aspects of history and class consciousness. London: Routledge and Kegan Paul, 1971.

MÉSZÁROS, István. The necessity of social control. London: Merlin, 1971. (Edição brasileira: MÉSZÁROS, István. A necessidade de controle social. Trad. Mário Duayer. São Paulo: Ensaio, 1987.)

MÉSZÁROS, István. Lukács' concept of dialectic. London: Merlin Press, 1972. (Edição brasileira: MÉSZÁROS, István. 0 conceito de dialética em Lukács. Trad. Rogério Bettoni. São Paulo: Boitempo, 2013.)

MÉSZÁROS, István. Neocolonial identity and counter-consciousness: essays on cultural decolonization. London: Merlin Press, 1978.

MÉSZÁROS, István. The work of Sartre: search for freedom. Brighton: Harvester Wheatsheaf, 1979. (Edições brasileiras: 1) MÉSZÁROS, István. A obra de Sartre: busca da liberdade. Trad. Lólio Lourenço de Oliveira. São Paulo: Ensaio, 1991; 2) MÉSZÁROS, István. A obra de Sartre: busca da liberdade e desafio da história. Trad. Rogério Bettoni. São Paulo: Boitempo, 2012).

MÉSZÁROS, István. Philosophy, ideology and social science: essays in negation and afirmantion. Sussex: Wheatsheaf Books, 1986. (Edições brasileiras: 1) MÉSZÁROS, István. Filosofia, ideologia e ciência social: ensaios de negação e afirmação. Trad. Laboratório de traduções do CENEX/FALE/UFMG. São Paulo: Ensaio, 1993; 2) MÉSZÁROS, István. Filosofia, ideologia e ciência social: ensaios de negação e afirmação. Trad. Ester Vaisman. São Paulo: Boitempo, 2008). 
MÉSZÁROS, István. Produção destrutiva e Estado capitalista. Trad. Georg Toscheff. São Paulo: Ensaio, 1989.

MÉSZÁROS, István. The power of ideology. Brighton: Harvester Wheatsheaf, 1989. (Edições brasileiras: 1) MÉSZÁROS, István. 0 poder da ideologia. Trad. Magda Lopes. São Paulo: Ensaio, 1996; 2) MÉSZÁROS, István. O poder da ideologia. Trad. Paulo Cesar Castanheira. São Paulo: Boitempo, 2004.)

MÉSZÁROS, István. Beyond capital: towards a theory of transition. London: Merlin Press, 1995. (Edição brasileira: MÉSZÁROS, István. Para além do capital: rumo a uma teoria da transição. Trad. Paulo Cesar Castanheira e Sérgio Lessa. São Paulo: Boitempo, 2006.)

MÉSZÁROS, István. Socialism or barbarism: from the 'American Century' to the crossroads. New York: Monthly Review, 2001. (Edição brasileira: MÉSZÁROS, István. O século XXI: socialismo ou barbárie? Trad. Paulo Cesar Castanheira. São Paulo: Boitempo, 2003.)

MÉSZÁROS, István. A educação para além do capital. Trad. Isa Tavares. São Paulo: Boitempo, 2005.

MÉSZÁROS, István. 0 desafio e o fardo do tempo histórico: o socialismo no século XXI. Trad. Ana Aguiar Cotrim e Vera Aguiar Cotrim. São Paulo: Boitempo, 2007. (Edição americana: MÉSZÁROS, István. The challenge and burden of historical time: socialism in the twenty-first century. New York: Monthly Review, 2008.)

MÉSZÁROS, István. A crise estrutural do capital. Trad. Francisco Raul Cornejo et all. São Paulo: Boitempo, 2009. (Edição americana: MÉSZÁROS, István. The structural crisis of capital. New York: Monthly Review, 2010.)

MÉSZÁROS, István. Estrutural social e formas de consciência: a determinação social do método. Trad. Luciana Pudenzi, Francisco Raul Cornejo e Paulo Cesar Castanheira. São Paulo: Boitempo, 2009. (Edição americana: MÉSZÁROS, István. Social Structure and Forms of Consciousness I: the social determination of method. New York: Monthly Review, 2010.)

MÉSZÁROS, István. A atualidade histórica da ofensiva socialista: uma alternativa radical ao sistema parlamentar. Trad. Paulo Cesar Castanheira. São Paulo: Boitempo, 2010.) 
MÉSZÁROS, István. Estrutural social e formas de consciência II: a dialética da estrutura e da história. Trad. Rogério Bettoni. São Paulo: Boitempo, 2012. (Edição americana: Social Structure and Forms of Consciousness II: the dialectic of structure and history. New York: Monthly Review, 2011.)

MÉSZÁROS, István. A montanha que devemos conquistar: reflexões acerca do Estado. Trad. Maria Izabel Lagoa. São Paulo: Boitempo, 2015.

MÉSZÁROS, István. Para além do Leviatã. São Paulo: Boitempo, no prelo. 